\title{
Evaluated Activity Relationship
}

National Cancer Institute

\section{Source}

National Cancer Institute. Evaluated Activity Relationship. NCI Thesaurus. Code C93462.

Specifies the link between an adverse event causal assessment and the activity evaluated as a possible cause. 